\title{
Classifying Values by Categories
}

\author{
Mevlüt Gündüz \\ Correspondence: Mevlüt Gündüz, Faculty of Education, Süleyman Demirel University, Isparta, Turkey.
}

Received: July 25, $2016 \quad$ Accepted: August 25, $2016 \quad$ Online Published: September 13, 2016

doi:10.11114/jets.v4i10.1765 URL: http://dx.doi.org/10.11114/jets.v4i10.1765

\begin{abstract}
The aim of this study is to make a new classification regarding the fact that the current classifications may change constantly because of values' gaining a different dimension and importance every single day. In this research descriptive research, which was used frequently in qualitative research methods, was preferred. This research was conducted with the participation of 1394 participants. These participants are 350 teachers working in Isparta provience, 190 students studying at Suleyman Demirel University Education Faculty, 454 candidate teachers who graduated and studying for the exam of KPSS and 400 primary school students in the 2014/2015 education years. All of the data in the research were obtained through "Semi-Structured Interview Form" prepared by the researcher consisting of open-ended questions. Four expert opinions were asked for in order to ensure the reliability of the research. In comparisons the numbers of consensus and disagreement the reliability of studies was calculated by using Miles and Huberman formula (Reliability=consensus /consensus+disagreement) and $91 \%$. Agreement has been reached. According to the findings obtained, religious, personal, national, knowledge-based and universal values were grouped under introversive values in accordance with participants' opinions. The remaining communal, humanistic, familial, social, and environmental values were treated as extroversive values. When it was compared with the other researches religious, personal,,national, universal, humanistic, social, and environmental values were seen as common.
\end{abstract}

Keywords: values education, values, classification of values

\section{Introduction}

With the recent increase in the importance of values education, there has also been an increase in the studies conducted in this area (Akbaş, 2004; Dilmaç, 2007; Ulusoy, 2007; Keskin, 2008; Aladağ, 2009; Yiğittir, 2009; Çengelci, 2010; Tahiroğlu, 2011; Ülger, 2012; Gündüz, 2014).

Values come first among the phenomena that tie the society and maintain it. Values have been an issue of curiosity as they contain various characteristics. Particularly, the affective dimension of values has been tried to enlighten by several studies (Özsoy, 2007). Recently, such topics as values education, moral education, citizenship education, ethics, classification of values, establishing empathy, sex education, drug education, and religious education have become prominent.

According to Schwartz and Bilsky, who have conducted significant researches in order to identify values (referred: Kuşdil and Kağıtçıbaşı, 2000), values are beliefs. However, values do not have the quality of an idea which is completely objective and devoid of sense; they become intertwined with senses when they are activated. Based on this description, we can say that values are uniting phenomena adopted by society or individuals and are criteria believed to meet the social needs of the society and for the welfare of individuals, and are attitudes concerning not only the conscious, but emotions and excitements as well, and that they are the motives guiding the behaviour in the conscious of the individual (Özgüven, 1994).

Values have a property of affecting and of being affected by each other. Values such as respect, love, tolerance, and helpfulness cannot be considered as separate things. There is a mutual relationship between each value and it is not correct to draw a certain line between values (Şen, 2007). Using multiple views to define values proved effective in classifying values. Different classifications of values were made by different people. Therefore, one cannot say that there is a classification of values accepted in common (Aslan, 2011). Nevertheless, researchers still categorized values in terms of certain properties.

Although various researches have been conducted on the classification of values, new values emerge in the changing structure of society and in the evolving world. For this reason, classification of values might be needed in different time 
periods of time taking different variables into account. Thus, classification of values will enable this field to gain importance and it will reveal its unknown sides.

Lickona (1991) classified values as moral and amoral values, Rokeach (1973) as purpose and means values, Spranger (referred: Akbaş, 2004) as political, social, theoretical, economical, religious, aesthetic; Schwartz (1992) defined values as 10 types of values consisting of power, success, getting pleasure from life, stimulation, self-orientation, universality, helpfulness, traditionalism, obedience, and safety by utilizing multiple values of culture, Nelson (1974) classified values as individual, group, and social values (refered: Naylor and Diem,1987).

Güngör (1998) classified values as aesthetic, theoretical, financial, political, and religious values; Kale (2004) as universal and cultural values, Ercan (2001) as national and universal values, Canatan (2004) as traditional and modern values. Acat and Aslan (2012) made the last classification in the literature as conservative-traditional, national-civil, self-oriented-personal, social-communal, and scientific-innovative.

Although there are various classifications of values, as far as the studies conducted about values both in-country and abroad, Schwartz's classification is used more extensively.

The purpose of this paper is to make a new classification considering the fact that current classifications can always change owing to values' gaining a different dimension and gaining importance every single day. Every classification about values contributes to the field of values and enables this field to improve. Since the field of values education is broad and versatile, new points of view and perceptions will emerge thanks to these new classifications, thus shedding light on later studies.

\section{Method}

\subsection{Research Design}

In this descriptive research, a survey, with open-ended and close-ended questions, was used in data collection process. Descriptive researches are carried out to describe the features of phenomena on a study (Borg, Gall \& Gall, 1993). Close-ended questions are used when collecting data about the demographic information of participants; and open-ended questions are used to collect data about the values of participants. Data gathered through open-ended questions, are classified into themes by using qualitative data analysis methods; themes and other answers are presented in frequency rates.

\subsection{Research Group}

This research was conducted in 2014-2015 academic year by the participation of 350 teachers assigned in the provience of Isparta, 190 candidate teachers studying in the Department of Education in Süleyman Demirel University, 454 graduated teachers, who are preparing for the PPSE, 400 primary school students, with a total number of 1394 participants. Voluntariness was taken a basis in the research and the identities of the participants were kept confidential. There variations among participants in terms of gender, place of residence, and type of participation. According to Yıldırım and Şimşek (2011), the fact that the researcher describes individuals and the data source for the research, is adequately a measure which increases the external reliability of the research. Personal information belonging to the participants was given in Table 1 elaborately.

Table 1. Personal Information of the Participants

\begin{tabular}{llll}
\hline Gender & Male & & Female \\
& 726 & 668 & \\
\hline Place of Residence & City Centre & County & Village \\
& 703 & 379 & 312 \\
\hline Type of the Participant & Teacher & Prospective Teacher & Student \\
& 350 & 644 & 400 \\
\hline
\end{tabular}

\subsection{Data Collection}

All the data in the research was obtained through "Semi-structured Interview Form", consisted of open-ended questions developed by the researcher. Semi-structured Interview technique seems to be a more appropriate technique in the researches for educational science because of the standard, that it has to some extent and also its flexibility (Ekiz, 2003). In the preparation of the form, literature was reviewed first, then the interview questions for pre-application in accordance with the findings obtained. Four experts were consulted for their opinion on the form and after the feedbacks, some of the questions were removed and form took its final version at the end of the pre-application carried out with 25 people. The strategy used to increase reliability was explained plainly and thus it enabled other researchers to use the strategy in a similar way (Silverman, 2000; Yıldırım and Şimşek, 2011). In the research, by reporting all the stages elaborately and clearly, the external reliability was increased; and by trying to convince the reader by way of adding comments to the results of the research, the internal reliability of the research was also increased. Additionally, 
by presenting some of the findings exactly as they are, the internal reliability of the research was increased significantly (Türnüklü, 2001; Robson, 1999). Four experts were consulted for their opinion in order to ensure the reliability of the research. The number of agreement and disagreement in the comparisons were identified and the reliability of the research was calculated using Miles and Huberman's (1994) formula (Reliability=agreement/agreement+disagreement). Thus, $91 \%$ of reconciliation rate was obtained in the reliability study conducted for this research.

\subsection{Data Analysis}

Data were analyzed using content analysis technique. The purpose of content analysis is to reach concepts and relations in order to explain the data gathered. Data were analyzed in four sections in content analysis. These are; coding, finding the themes, arranging the codes and themes, defining and interpreting them. In the coding step, the researcher analyzes the data obtained and divides them into meaningful parts. In finding the themes phase, codes are arranged first and then the relations are found. Then, the codes are classified and a structure was formed in order to arrange them. In the last process, data obtained according to this structure are interpreted (Yıldırım and Şimşek, 2011).

\section{Results}

This study conducted in order to make a new classification of values according to the opinions of the participants, these findings below were obtained from the interview form the participants filled in.

Table 2. Classification of values according to the opinions of the participants

\begin{tabular}{lll}
\hline Classification & Kinds of value & Frequency \\
\hline \multirow{2}{*}{ Introversive } & Religious values & 174 \\
& Personal values & 453 \\
& National values & 84 \\
& Knowledge-based values & 131 \\
& Universal values & 119 \\
\hline \multirow{2}{*}{ Extroversive } & Communal values & 114 \\
& Humanistic values & 163 \\
& Familial values & 67 \\
\hline
\end{tabular}

In Table 2, values, which were obtained from the answers of the participants, were created and these were given numbers of frequency by making their classification. Values were grouped in terms of a person's being introverted $(n=961)$ and extroverted $(n=433)$. Among the introversive values, the most mentioned one was personal values $(n=453)$, and among the extroversive values, the most mentioned one was humanistic values $(n=163)$. The fact that a person was more affected by the introversive values among the values s/he has, and the fact that both s/he and more people were affected by extroversive values were taken into consideration.

\subsection{Findings about Values a Person Creates Introversively}

Table 3. Findings about religious values

\begin{tabular}{llll}
\hline Value & Frequency & Value & Frequency \\
\hline Belief & 5 & Shame & 3 \\
Morality & 5 & Faith & 18 \\
Honor & 34 & Cleanliness & 2 \\
Spirituality & 4 & Thankful & 2 \\
Religionist & 3 & Inner Beauty & 3 \\
Chastity & 2 & Humbleness & 2 \\
Fairness & 2 & Virginity & 10 \\
Strong-Willed & 1 & Fear of God & 3 \\
Modesty & 1 & Contented & 1 \\
Learning Qur'an & 2 & Agreeing with one's right & 1 \\
Knowing the Prophets & 5 & Toleration & 2 \\
Being Grateful & 2 & Greedy & 1 \\
Conscience & 29 & Decency & \\
Wisdom & 1 & Obedient & \\
Love & 3 & & \\
\hline
\end{tabular}

In Table 3, the frequency numbers of the values, named under religious values, were included. Among the religious values grouped with the opinions of 174 people, honor $(n=34)$, conscience $(n=29)$, decency $(n=26)$, and then faith $(n=18)$ are the ones that are included most.

Considering the answers of the participants, it can be seen that the values in the table above are the ones based on religion. Values are made up of various components, one of the most important of which is religion. Rather, it is known that values are made stronger by religion and that religious factors dominate values. Values such as honor, conscience, decency, faith, fear of God, knowing the prophet, belief, and morality come first among the ones that people in society 
can accept or regard as values. Religious values are regarded as significant by people and they constitute the basis of other values. The bases of a lot of values such as fairness, honesty, love, responsibility, helpfulness, and respect refer to religion. Religious values have always been included in many studies that classify values (Lickona, 1991; Spranger, refered: Akbaş, 2004; Schwartz, 1992; Güngör, 1998; Acat and Aslan, 2012).

Table 4. Findings about personal values

\begin{tabular}{|c|c|c|c|}
\hline Value & Frequency & Value & Frequency \\
\hline Able to express himself/herself & 4 & Imagining & 1 \\
\hline Seriousness & 3 & Dignity & 12 \\
\hline Honor & 13 & Sedate & 5 \\
\hline Punctual & 3 & Planned & 1 \\
\hline Prescient & 4 & Idealist & 8 \\
\hline Awareness & 2 & Shy & 6 \\
\hline Combative & 5 & Stable & 4 \\
\hline Thrifty & 6 & Being as $s / h e$ is & 4 \\
\hline Self-knowledge & 14 & Healthy & 3 \\
\hline Calm & 9 & Moderate & 2 \\
\hline Not being imbalanced & 6 & Natural & 7 \\
\hline Talking by thinking first & 9 & Funny & 4 \\
\hline Cheerful & 7 & Lovely & 4 \\
\hline Being tidy & 6 & Macho enough & 2 \\
\hline Smiling & 7 & The joy of living & 7 \\
\hline Meticulous & 6 & Gentleman & 8 \\
\hline Thoughtful & 8 & Courageous & 9 \\
\hline Sportsman & 3 & Self-confidence & 9 \\
\hline Agreeable & 8 & Sensual & 9 \\
\hline Feminist & 2 & Determined & 8 \\
\hline Steadiness & 7 & Earnest & 11 \\
\hline Unbiased & 4 & Cold-blooded & 3 \\
\hline Manful & 10 & Conscious & 5 \\
\hline Submissive & 9 & Knowing his/her task & 3 \\
\hline Dignity & 10 & Venturous & 1 \\
\hline Proud & 27 & Purpose & 4 \\
\hline Determination & 9 & Organisation & 7 \\
\hline Consistent & 4 & Disciplined & 15 \\
\hline Honorable & 29 & Anger-management & 10 \\
\hline Calm & 7 & Dressing well & 9 \\
\hline Handsome & 1 & Having a good profession & 3 \\
\hline Appreciate himself/herself & 6 & $\begin{array}{l}\text { Principled } \\
\text { Prich }\end{array}$ & 2 \\
\hline Making mistakes, not making errors & 4 & Self-sensitivity & 7 \\
\hline Appealing & 3 & & \\
\hline
\end{tabular}

In Table 4, the frequency numbers of the values, named under personal values, were included. Among the personal values grouped with the opinions of 453 people, honorable $(n=29)$ and proud $(n=27)$ were stated most.

By means of the opinions of the participants, the values in the table can be considered to be personal or self-oriented. As it is known, values have both an internal and an external aspect. These are hard to be distinguished from one another because people's emotions are affected by every change since they are social beings. In some conditions, internal emotions can affect external emotions and external emotions can affect internal emotions. Thus, regarding a person as a whole being would always enable the right interpretation easier.

Values such as being proud, acting honourable, having honour, knowing oneself, being manful, being disciplined, and being earnest are among the values that most people adopt commonly. Actually, these values are among the essential ones that make people who they are, and shape the personality. When we look into the studies on classification of values, it can be seen that the personal or self-oriented values are included in those (Nelson, 1974, refered: Naylor and Diem, 1987; Acat and Aslan, 2012).

Table 5. Findings about national values

\begin{tabular}{|c|c|c|c|}
\hline Value & Frequency & Value & Frequency \\
\hline Patriot & 16 & National awareness & 11 \\
\hline National spirit & 6 & Nationalist & 15 \\
\hline Country-nation & 2 & Knowing his/her past & 9 \\
\hline Tied to customs and traditions & 4 & Civilization & 1 \\
\hline Knowing the customs and traditions & 2 & Protecting his/her culture & 5 \\
\hline Knowing where s/he came from & 4 & Knowing his/her ancestor & 2 \\
\hline Tied to his/her history & 5 & Respect for the police and the soldiers & 2 \\
\hline
\end{tabular}

In Table 5, the frequency numbers of the values, named under national values, were included. Among the national 
values grouped with the opinions of 84 people, patriot $(n=16)$, nationalist $(n=15)$, and national awareness $(n=11)$ were identified most.

According to the answers of the participants, the geographical regions and country lands play a great part in constituting values and culture. People, by nature, are emotionally tied to the place they are living in. Thanks to this, the feeling of national unity and solidarity comes out. When we regard a person as a whole being, not only the period of time s/he is in, but also his/her past, and moral values as national values, custom and traditions, culture, his/her ancestors, patriotism, national conscience, and nationalism count. Cultural and national values are included in the classification of values (Kale, 2004; Ercan, 2001; Acat and Aslan, 2012).

Table 6. Findings about knowledge-based values

\begin{tabular}{llll}
\hline Value & Frequency & Value & Frequency \\
\hline Logical & 3 & Attention & 3 \\
Questioning & 35 & Multilateral thinking & 2 \\
Creative & 25 & Authentic & 1 \\
Educated & 4 & Having background & 2 \\
Successful & 5 & Having an aim & 2 \\
Knowing what s/he wants & 2 & Thinking holistically & 3 \\
Curious & 2 & Enjoying learning & 2 \\
Open to changes & 1 & Knowledgeable & 10 \\
Investigative & 2 & Wisdom & 3 \\
Hardworking & 2 & Literate & 1 \\
Thinking analytically & 3 & Entrepreneur & 21 \\
\hline
\end{tabular}

In Table 6, the frequency numbers of the values, named under knowledge-based values, were included. Among the knowledge-based values grouped with the opinions of 131 people, questioning $(n=35)$, creative $(n=25)$, and entrepreneur ( $\mathrm{n}=21)$ were ideintified most.

According to the opinions of the participants, it can be seen that the values that make people who they are are not only the values such as respect, love, tolerance, responsibility, patience, helpfulness, fairness, but there are also the values based on a person's improving himself/herself. Since a human is a learning being, s/he wants to realize himself/herself and combine knowledge with his/her feelings. Actually, people's cognitive and affective aspects are two factors that complement each other in the forming of value.

People do not accept things as they are when forming value judgment. Especially in terms of knowledge, people question any knowledge by nature, criticize, so they are always in that state of venture. They sometimes set an example for other people by reaching the ideas that no one cannot think of. Therefore, there is nothing more natural than a person improving himself/herself. So, in a person improving and realizing himself/herself, there are such values in terms of knowledge as entrepreneurship, curiosity, questioning, creative thinking, and analytic thinking. This kind of values is included in the classification of values (Schwartz, 1992; Acat and Aslan, 2012).

Table 7. Findings about universal values

\begin{tabular}{llll}
\hline Value & Frequency & Value & Frequency \\
\hline Honesty & 17 & Helpfulness & 8 \\
Love & 14 & Respect & 7 \\
Sacrifice & 6 & Responsibility & 9 \\
Kindness & 4 & Tolerance & 11 \\
Mercy & 2 & Freedom & 1 \\
Trust & 5 & Fairness & 9 \\
Virtue & 3 & Affection & 4 \\
Loyalty & 2 & Modest & 2 \\
Self-respect & 6 & Fidelity & 3 \\
Generosity & 5 & Happiness & 1 \\
\hline
\end{tabular}

In Table 7, the frequency numbers of the values, named under universal values, were included. Among the universal values grouped with the opinions of 119 people, honesty $(n=17)$, love $(n=14)$ and tolerance $(n=11)$ were idenitified most.

We can call the values accepted worldwide and take cared by most people as universal values. Humans, by nature, have some feelings inside no matter what religion they are a member of, what nationality they are from and which race they belong to. Actually, these feelings are a superiority that makes people who they are, and that discriminates humans from other livings. Therefore, if a person is deprived of such feelings as honesty, love, tolerance, helpfulness, respect, responsibility, fairness, trust, and sacrifice, it will be hard for people, who are social beings, to live together. The universal values included in the table above and are adopted by most people have always been taken into account by researchers (Schwartz, 1992; Kale, 2004; Ercan, 2001; Canatan, 2004). 


\subsection{Findings about Values a Person Creates Extroversively}

Table 8. Findings about communal values

\begin{tabular}{llll}
\hline Value & Frequency & Value & Frequency \\
\hline Obeying the rules & 6 & Being respectable & 3 \\
Being useful for the society & 14 & Solidarity & 6 \\
Helping each other & 9 & Cooperation & 4 \\
Sharing & 5 & Dignity & 10 \\
Manners & 3 & Be of good manners & 5 \\
Being a leader & 4 & Unity & 7 \\
Political tolerance & 1 & Reconciled with society & 3 \\
Not harming others & 2 & Democratic & 13 \\
Money & 7 & Respect for the disabled & 3 \\
Respect for the elderly and the patients & 9 & &
\end{tabular}

In Table 8, the frequency numbers of the values, named under communal values, were included. Among the universal values grouped with the opinions of 114 people, being useful for the society $(n=14)$, democratic $(n=13)$ and dignity $(\mathrm{n}=10)$ were stated most.

According to the answers of the participants, when we look at the values people possess, we can see that both individual and communal values shape humans. Communal values are of vital importance for people to live together and for other values to emerge because people cannot be considered as separate from the environment they live in. Though people form some values by themselves, other values emerge from the obligation of people to live together. In this context, we can consider the communal values as the field of application of other values. Values such as being useful for the society, being democratic, being respected, respecting the elderly and the patient, helping each other, and solidarity can be regarded as the field of application of many values.

Communal values are not included with this name in many of the classifications of values. Usually, communal values are dealt with as social values (Nelson, 1974, refered: Naylor and Diem, 1987; Spranger, refered: Akbaş, 2004; Güngör, 1998; Acat and Aslan, 2012).

Table 9. Findings about humanistic values

\begin{tabular}{llll}
\hline Value & Frequency & Value & Frequency \\
\hline Loving the created ones owing to the creator & 2 & Treating without judgement & 1 \\
Not having malicious intentions & 5 & Positive thinking & 1 \\
Endearment & 3 & Eloquence & 2 \\
Benevolent & 8 & Loving people & 1 \\
Caring & 3 & Keeping his/her promise & 6 \\
Respect for human rights & 5 & Ability to communicate & 4 \\
Mature & 9 & Not classifying people & 4 \\
Being a decent person & 5 & Naïve & 5 \\
Not tolerating racism & 6 & Not eating his/her words & 10 \\
Respect for feelings & 4 & Telling people humanely the people & 5 \\
Not discriminating & 3 & Respect for religious duties & 10 \\
Not hurting even an ant & 2 & Uncorrupted & 17 \\
Being the real man & 17 & Having his/her share of mankind & 3 \\
Accepting people as they are & 22 & &
\end{tabular}

In Table 9, the frequency numbers of the values, named under humanistic values, were included. Among the humanistic values grouped with the opinions of 163 people, accepting people as they are $(n=22)$, being the real man $(n=17)$ and uncorrupted $(\mathrm{n}=17)$ were specified most.

When we consider the numbers in the table in line with the opinions of the participants, it can be said that there are some values that both enable one's self-respect and ease his/her adaptation to society. In line with the increase in the value of humans in a humanist society, it can be said that some new conceptions of values have started to take part in the literature. For instance, values such as 'being the real man', 'having one's share of humanity', 'telling people humanely to the people', 'not eating one's words', 'not hurting even an ant' are used more and more now. These types of values reflect the value given to people and they imply that new values can emerge day by day.

Humanistic values were accepted by society and took their parts in the classification of values (Rokeach, 1973; Lickona, 1991; Schwartz, 1992; Acat and Aslan, 2012).

Table 10. Findings about familial values

\begin{tabular}{llll}
\hline Value & Frequency & Value & Frequency \\
\hline Devotion to family & 13 & Hospitable & 6 \\
Visit & 1 & Family affairs & 6 \\
Kinship & 4 & Well-mannered & 19 \\
Protective & 6 & Protective & 3 \\
Caring & 3 & Loving the youngsters \\
Belonging & 2 & & 4 \\
\hline
\end{tabular}


In Table 10, the frequency numbers of the values, named under familial values, were included. Among the familial values grouped with the opinions of 67 people, well-mannered $(n=19)$ and devotion to family $(n=13)$ were stated most.

In accordance with the opinions of the participants, familial values come first among the significant values in society. Constituting the building block of society, family has always kept its importance on account of its sensitive values because people communicate firstly with family members and it is here that they gain their first values. Then, they interiorize these values by transferring the values they gained to society and by interacting with new people. Essential values such as devotion to family, kinship, protectiveness, hospitality, family affairs, and family discipline, all having an important place in familial values, continue to keep their importance for both individuals and society. Again, there are not many classifications as familial values in the classifications of values. With similar names, there are such values as traditionalism, cultural, and conservatism (Schwartz,1992; Kale, 2004; Canatan , 2004; Acat and Aslan ,2012).

Table 11. Findings about social values

\begin{tabular}{llll}
\hline Value & Frequency & Value & Frequency \\
\hline Social & 12 & Empathy & 21 \\
Friendly & 2 & Easy-going & 2 \\
Able to listen & 3 & Not being selfish & 5 \\
Amiable & 1 & altruism & 4 \\
Not being egocentric & 6 & Not being self-seeker & 9 \\
\hline
\end{tabular}

In Table 11, the frequency numbers of the values, named under social values, were included. Among the social values grouped with the opinions of 65 people, empathy $(n=21)$ and social $(n=12)$ were stated most.

According to the opinions of the participants, besides the self-oriented values people have, there are also extroversive and social values. These values are as significant as introversive values because people, by nature, have to socialize and live together with others. Forming good relationship with people strengthens both people's social and emotional aspects. Considered as a whole, a human is a bio-psycho-social being. As a matter of fact, if people act selfishly and thus get far away from others, other values also will be affected negatively. However, the value perception of the people who develop empathy, form friendly relationships, and are altruist will always be more positive.

When we look at the researches on the classification of values, we see that social values have always maintained its significance (Spranger, refered: Akbaş, 2004; Nelson, 1974, refered: Naylor and Diem,1987; Güngör, 1998; Acat and Aslan, 2012 ).

Table 12. Findings about environmental values

\begin{tabular}{ll}
\hline Value & Frequency \\
\hline Environmentalist & 2 \\
Animal lover & 5 \\
Nature lover & 3 \\
Nature conscious & 14 \\
\hline
\end{tabular}

In Table 12, the frequency numbers of the values, named under environmental values, were included. Among the environmental grouped with the opinions of 24 people, nature conscious $(n=14)$ was stated most.

According to the statements of the participants, a new conception of values emerged which was not included much in the classification of values and which can pave the way for later researches on values. When we say 'value', the first thing that comes to mind is attitudes and behaviours resulting from a person's self-oriented interaction or the interactions with other people. However, there are also values that people should maintain such as being conscious for environment, protecting animals, adopting the nature. The perception of value granted to people will, of course, show itself for other living things.

\section{Discussion}

This study conducted in order to make a new classification and to constitute a new perception in value education based on the opinions of teachers, candidate teachers, and primary school students, and these following results were obtained from the findings in accordance with the answers of the participants:

Values, which play an important part in ensuring the continuity and the peace of the society, have recently been paid more attention (Özsoy, 2007). Especially, considering the events occurring recently in the society, people have started to talk about the issue 'Are we losing our values?' (Sulak, Gündüz and Kemiksiz, 2015), since it is significant to be aware of our values and to protect them for the future of our society.

The outlook for values can change in time in our changing and developing social structure and new perceptions of values can emerge, which increase the importance of researches conducted on value (Gündüz, 2014; Ülger, 2012; Tahiroğlu, 2011; Çengelci, 2010; Yiğittir, 2009; Aladağ, 2009; Keskin, 2008; Ulusoy, 2007; Dilmaç, 2007; Akbaş, 2004). Especially, new dimensions are handled in terms of classifying values (Acat and Aslan, 2012). While some researchers see the values as end and means values (Rokeach, 1973), others may see them as national and universal values (Ercan, 2001). While some classifications of value are included in all researches, different classifications of value may also be 
included. This situation points out that new classifications can always be made by considering the perception of value from wide and different perspectives.

When we look at the literature, it can be seen that both in Turkey (Güngör, 1998; Ercan, 2001; Kale, 2004; Canatan, 2004; Acat and Aslan, 2012) and across the world (Rokeach, 1973; Nelson, 1974, refered: Naylor and Diem, 1987; Lincona, 1991; Schwartz, 1992; Spranger, refered: Akbaş, 2004), there are some researchers who make different classifications of value. However, one can never talk about any clear classification of value agreed by everyone (Aslan, 2011).

A new classification of values was carried out in this study with a new perspective and the aim has been to contribute to later classifications of values. In accordance with the opinions of the participants, religious, personal, national, knowledge-based, and universal values were grouped under the name of introversive values. The rest, communal, humanistic, familial, social, and environmental values were regarded as extroversive values. Compared with the other researches, it can be seen that values such as religious, personal, national, universal, humanistic, social, and communal values are common, which shows that values are adopted commonly by society whether or not there are different perspectives in the classification of values. Again, new classifications of values such as familial, knowledge-based, and environmental can arise. Thus, it has been seen that new perceptions of value can also arise in our changing and developing modern society (Acat and Aslan, 2012).

Another significant result in the classification of values was that although new classification of values was made in various researches, some values could still be included in more than one category as they are versatile and interaction-dependent (Şen, 2007). Since the perception of value is an affective and relative situation, it is open to analyse from many different perspectives. For instance, it is not right to put some values into a certain class such as helpfulness, tolerance, being earnest, being kind, being virtuous, being honest, patience, generosity, and conscience because these values may be included in more than one group of value at the same time, for they have a wide scope of influence by nature. Moreover, it has been understood that many values are made stronger by religion and that it can be an axis (a focal point) among other values.

In conclusion, this study has shown that since the perception of values is a versatile component, new dimensions may always emerge. Thus, although different values are adopted by people based on culture, religion, and similar causes, common values will always take their parts in studies as the need of being human in a universal dimension. The fact that society undergoes changes day by day in terms of technology, knowledge, and culture will, of course, contribute to the emergence of new values. If we consider these newly emerged values as wealth and if we can enable them to be coherent with unchanging basic values, the society will always maintain its permanence.

\section{References}

Acat, M. B., \& Aslan, M. (2012). A new classification of value and the values students should gain depending on this classification, Education Science in Theory and Practice (ESITP), 12(2) 1460-1474

Akbaş, O. (2004). Evaluating the Level of Realization of Affective Purposes in II. Grade in Turkish National Education System, Unpublished PhD Thesis, Gazi University, Institute of Education Sciences, Ankara

Aladağ, S. (2009). The Effect of Value Education Approaches in Teaching Primary School Social Studies on the Level of Students' Gaining the Value of Responsibility, Unpublished PhD Thesis, Gazi University, Institute of Education Sciences, Ankara

Aslan, M. (2011). Character Education in Primary School and the Values to Make Students Gain, Unpublished PhD Thesis, Osmangazi University, Institute of Education Sciences, Eskişehir.

Borg, W. R., Gall, J. P., \& Gall, M. D. (1993). Applying educational research: A practical guide. White Plains, NY: Longman.

Canatan, K. (2004). Tendency for Values in European Union Countries, The Journal of Values Education, 2(7-8), 41-63

Çengelci, T. (2010). A Case Study for Realizing Values Education in Primary School 5th Grade Social Studies Lesson, Unpublished PhD Thesis, Anadolu University, Institute of Education Sciences, Eskişehir.

Dilmaç, B. (2007). Testing Humanistic Values Education Given to a Group of Science High School Students with Humanistic Values Scale, Unpublished PhD Thesis, Selçuk University, Institute of Social Sciences, Konya.

Ekiz, D. (2003). Introduction to Research and Project Methods in Education, Ankara: Anı Publishing

Ercan, İ. (2001). National and Universal Values in Primary School Social Studies Program, Unpublished Master's Thesis, Onsekiz Mart University, Institute of Social Sciences, Çanakkale

Gündüz, M. (2014). The Effect of Teaching the Value of "Responsibility" Through the Project-Based Approach in 
Primary School 3rd Grade Social Studies Lesson on Academic Success and Attitude, Unpublished PhD Thesis, Gazi University, Institute of Education Sciences, Ankara.

Güngör, E. (1998). Researches on Values Psychology, İstanbul: Ötüken Publishing

Kale, N. (2004). What Kind of a Value Education, Values and Education International Symposium, Values Education Central Publishing, İstanbul.

Keskin, Y. (2008). Values Education in Social Studies in Turkey: Historical Development, Researching 1998 and 2004 Programs'Effectiveness, Unpublished PhD Thesis, Marmara University, Institute of Education Sciences, İstanbul.

Kuşdil, M. E., \& Kağıtçıbaşı, Ç. (2000). Value Tendency of Turkish Teachers and Schwartz Value Theory, Turkish Journal of Psychology, 45, 59-76

Lickona, T. (1991). Educating for Character: How our Schools can Teach Respect and Responsibility. Newyork: Bantam Books.

Miles, M. B., \& Huberman, A. M. (1994). Qualitative Data Analysis, Thousand Oaks, CA: Sage.

Naylor, D. T., \& Diem, R. (1987). Elementary and Middle School Social Studies, New York: Random House

Özgüven, İ. E. (1994). Psychological Tests, Ankara: Yeni Doğuş Press

Özsoy, S. (2007). Creating an Environment Based on Values Equals to Creating a Better World, First Teacher's Journal, $14,30-34$

Robson, C. (1999). Real World Research. Oxford: Blackwell.

Rokeach, M. (1973). The Nature of Human Values, New York: The Free Press

Schwartz, S. H. (1992). Universals in the Content and Structure of Values: Theoretical Advances and Empirical Tests in 20 Countries. Advances in Experimental Social Psychology, 25, 1-65. http://dx.doi.org/10.1016/S0065-2601(08)60281-6

Şen, Ü. (2007). A research on Value Education in Turkish Education Through 100 Fundamental Works the Ministry of Education Suggested in 2005, Master's Thesis, Gazi University, Institute of Education Sciences, Ankara.

Silverman, D. (2000). Doing Qualitative Research: A Practical Handbook. London: Sage.

Sulak, E. S., Gündüz, M., \& Kemiksiz, Ö. (2015). Determining the Values Being Increasingly Lost Today and a Qualitative Research on Developing Solution Suggestions for This Situation, Pursuit of Future in Education: The Symposium of Ability, Morality, and Values Education in Turkey from Past to Today, 16-18 April-Bartın

Tahiroğlu, M. (2011). Teaching the Values of Love for Nature, Cleanliness, and Being Healthy in Primary School 4th Grade Social Studies Lesson and Determining the Attitudes of Students towards Values, Unpublished PhD Thesis, Gazi University, Institute of Education Sciences, Ankara.

Türnüklü, A. (2001). Using Different Research Techniques together in Pedagogy in order to Answer the Same Research Question, Education and Science, 26(120), 8-13.

Ülger, M. (2012). Evaluating the Applications of Human Rights Citizenship Education in Primary Schools, Unpublished PhD Thesis, Gazi University, Institute of Education Sciences, Ankara

Ulusoy, K. (2007). Evaluating Student Attitudes and Opinions Towards the Traditional and Democratic Values in High School History Program in terms of various variables, Unpublished PhD Thesis, Gazi University, Institute of Education Sciences, Ankara.

Yiğittir, S. (2009). The Acquisition Level of the Values of Primary School 4th and 5th Grades Social Studies Lesson, Unpublished PhD Thesis, Gazi University, Institute of Education Sciences, Ankara.

Yıldırım, A., \& Şimşek, H. (2011). Qualitative Research Methods in Social Sciences, Ankara: Seçkin Publishing

\section{$(\mathrm{oc}) \mathrm{BY}$}

This work is licensed under a Creative Commons Attribution 3.0 License. 